\title{
Effect of Vitamin D on Bone Mineral Density Changes in Patients with Breast Cancer Receiving Adjuvant Aromatase Inhibitor Therapy
}

\author{
Sang Hoon Park, M.D. , Eun Young Kim, M.D., Ph.D.*, Chan Heun Park, M.D., Ph.D. \\ Department of Surgery, Kangbuk Samsung Hospital, Sungkyunkwan University School of Medicine, Seoul, Korea
}

Purpose: We assessed bone mineral density (BMD) changes with aromatase inhibitor (Al) treatment in women with breast cancer and determined whether BMD T-scores changed with vitamin D supplementation. Methods: This single-center, retrospective study included postmenopausal patients with breast cancer who had undergone surgical resection of stage I, II, or III estrogen- and/or progesterone-receptor-positive breast cancer and received adjuvant Als (letrozole, anastrozole, and exemestane) at Kangbuk Samsung Hospital from January 2003 to July 2017. Baseline BMD T-scores of the femoral neck, proximal femur, and lumbar spine were obtained. The first group received vitamin D oral supplements (25,000 IU, monthly) or intravenous (IV) injections (200,000 IU, every 6 months). The second group did not receive vitamin D. T-scores were re-assessed at 12 and 24 months. BMD changes in the femoral neck, proximal femur, and lumbar spine were examined and compared according to vitamin D therapy. Results: A total of 118 women were included in the study. Eighty-four patients $(71.2 \%)$ were aged $>50$ years, and most patients (64.1\%) were postmenopausal. Group $1(n=76,64.4 \%)$ had received vitamin $D$ oral supplements (25,000 IU, monthly) or IV injection (200,000 IU, every 6 months) during Al therapy. Group 2 ( $n=42,35.6 \%)$ did not receive vitamin D during Al therapy. At baseline, $42.2 \%$ and 28.6\% exhibited osteopenia at the femoral neck in Group 1 and Group 2, respectively. Both groups had T-score declines after Al therapy, with mean decreases of 0.23 and 0.41 at the femoral neck and lumbar spine, respectively, after 12 months and 0.40 and 0.55 at the femoral neck and lumbar spine, respectively, after 24 months in Group 1. However, differences in BMD T-score change at the femoral neck, total proximal femur, and lumbar spine between the groups were not statistically significant. Conclusion: Trends toward a decline in BMD in the femur and lumbar spine were observed in postmenopausal women with breast cancer receiving Al therapy. We did not observe a protective role of vitamin $D$ supplementation against bone loss with Al therapy. A longer follow-up duration is necessary to determine whether vitamin $\mathrm{D}$ protects against bone loss during Al therapy.

Key Words: Aromatase inhibitor, Bone density, Breast neoplasm, Vitamin D

\section{INTRODUCTION}

Breast cancer is the most common malignancy in women worldwide. More than half of breast cancer cases are hormone receptor (HR)-positive subtypes. Aromatase inhibitors (AIs) have become a mainstay of endocrine therapy in postmenopausal women with HR-positive breast cancer. AIs (letrozole, anastrozole, and exemestane) deplete circulating estrogens in postmenopausal women. However, major adverse events associated with AI use are musculoskeletal complaints such as bone loss, fractures, and joint pain or stiffness [1,2] Bone mineral density (BMD) testing and clinical assessments must be

Correspondence: Chan Heun Park, M.D., Ph.D.

Department of Surgery, Kangbuk Samsung Hospital, Sungkyunkwan University School of Medicine, 29 Saemunan-ro, Jongno-gu, Seoul 03181, Korea Tel: +82-2-2001-1730, Fax: +82-2-2001-1942, E-mail: chanheun1@gmail.com *These authors contributed equally to this work.

Received: Jul 6, 2019 Revised: Sep 16, 2019 Accepted: Oct 25, 2019 performed to monitor adverse effects of AI use.

Recently, the use of vitamin D has increased dramatically to prevent and treat bone-related disorders [3]. Vitamin D plays an essential role in calcium homeostasis and bone metabolism. Maintaining optimal plasma levels of 25-hydroxyvitamin D $(25(\mathrm{OH}) \mathrm{D})$ is strongly recommended in the general population and patients with breast cancer [4] Several guidelines have been developed to manage bone loss associated with AI use, including the role of vitamin D supplementation in these patients. The American Cancer Society/American Society of Clinical Oncology Breast Cancer Survivorship Care Guideline stated that supplementation with calcium (to achieve a total intake of 1,200 $\mathrm{mg} /$ day) and vitamin D3 (600-1,000 IU/day) for all adults aged >50 years is recommended [5]. NCCN bone health guideline also recommended that vitamin $\mathrm{D}$ should be supplemented in amounts sufficient to achieve a serum $25(\mathrm{OH}) \mathrm{D}$ level of $\geq 30 \mathrm{ng} / \mathrm{mL}$ (75 nmol/L) [6]. However, most studies were limited to healthy patients and published 
20-30 years ago [7,8]. Only a few studies have compared changes in BMD based on vitamin D supplementation in patients receiving AI therapy $[9,10]$.

Therefore, this study aimed to evaluate BMD at the total hip and lumbar spine in postmenopausal patients with breast cancer receiving adjuvant AI therapy and compare BMD changes according to vitamin D supplementation.

\section{METHODS}

\section{Patients}

This study retrospectively assessed data of postmenopausal patients with breast cancer who had undergone surgical resection of stage I, II, or III estrogen- and/or progesterone-receptor-positive breast cancer and received adjuvant AIs (letrozole, anastrozole, and exemestane) at Kangbuk Samsung Hospital from January 2003 to July 2017. Patients with any bone disorder (including fracture), missing data on BMD or vitamin D use, or distant metastases were excluded. Each patient's clinical, pathological, and radiological variables were evaluated. Group 1 had received vitamin D oral supplements (25,000 IU, monthly) or intravenous (IV) injection (200,000 IU, every 6 months) during AI therapy. Group 2 did not receive vitamin D during AI therapy. This single-institution retrospective study was approved by the Institutional Review Board (Kangbuk Samsung Hospital 2019-09-034).

\section{BMD}

BMDs at the femoral neck, proximal femur, and lumbar spine were evaluated at baseline and at 12 and 24 months using Hologic (Hologic, Bedford, USA) dual-energy x-ray absorptiometry (DEXA) after AI therapy. T-scores were calculated using manufacturer-specific T-score databases. Osteoporosis was defined as BMD more than 2.5 standard deviations (SD) below (as T-score $\leq-2.5 \mathrm{SD}$ ), osteopenia as T-score -1 to $-2.5 \mathrm{SD}$, and normal as T-score $\geq-1.0 \mathrm{SD}$, according to the WHO criteria. All DEXA devices were standardized and cross-calibrated using four Bio-Imaging Bona Fide Phantoms (CIRS Tissue Simulation and Phantom Technology, Norfolk, USA).

\section{Statistical analysis}

Qualitative variables were compared using the chi-squared or Fisher's exact test. Normally distributed quantitative variables were tested using a histogram. Student's t-test was used to compare the means after calculating the difference value. Multivariate analysis of data including age, menopausal status, prior adjuvant chemotherapy, prior and current bisphosphonate use, and baseline body mass index (BMI) was performed to compare the two groups using a generalized linear mixed model. All statistical analyses were performed using IBM SPSS Statistics software 21.0 (IBM, Armonk, USA), with statistical significance set at a $p$-value $<0.05$.

\section{RESULTS}

A total of 118 patients were included in the study. Eighty-four patients (71.2\%) were aged $>50$ years, and most patients (64.1\%) were postmenopausal. The mean age was $55.7 \pm 10.5$ years (range, $20-85$ years). Most patients had American Joint Committee on Cancer stage I (53.3\%) cancer and had received adjuvant chemotherapy (61.0\%). Seventy-three patients $(61.9 \%)$ had a BMI within the normal range (18.5-24.9) at baseline. Sixty-seven patients (56.8\%) had received letrozole, and 51 patients $(43.2 \%)$ had received anastrozole. The patients had no history of fracture. Patients in Group 1 were more likely to be younger and premenopausal, have received prior adjuvant chemotherapy, have normal weight, and have a lower BMI (all $p<0.05)$. The clinical and pathological characteristics of the two groups are presented in Table 1.

Table 2 shows the baseline BMD T-score measured prior to AI initiation and classified according to the femoral neck, total proximal femur, and lumbar spine. Approximately half of both groups had normal BMD in the femoral neck at baseline (Group 1, 52.6\%, vs. Group $2,52.4 \% ; p=0.037)$. More than two-thirds of patients in both groups had normal BMD in the proximal femur at baseline (Group 1, 82.9\%, vs. Group 2, 71.4\%; $p=0.061$ ). Approximately half of both groups had normal BMD in the lumbar spine at baseline (Group 1, 44.7\%, vs. Group 2, 54.8\%; $p=0.142$ ).

Table 3 shows BMD T-scores that were obtained at 12 months and 24 months after AI therapy and classified according to the femoral neck, total proximal femur and lumbar spine. Twelve months after AI therapy, the mean T-score in the femoral neck (-1.00 vs. -1.38 , $p=0.099)$ and the total proximal femur ( -0.09 vs. $-0.44, p=0.116)$ was higher in Group 1 compared to those in Group 2, and that in the lumbar spine ( -1.19 vs. $-1.13, p=0.819)$ was lower, all without statistically 
Table 1. Clinicopathologic characteristics of patients

\begin{tabular}{|c|c|c|c|c|}
\hline Characteristic & $\begin{array}{c}\text { All women } \\
(n=118) \\
\text { No. }(\%)\end{array}$ & $\begin{array}{l}\text { Group } 1 \\
(n=76) \\
\text { No. }(\%)\end{array}$ & $\begin{array}{l}\text { Group } 2 \\
(n=42) \\
\text { No. }(\%)\end{array}$ & $p$-value \\
\hline Age (yr) at diagnosis & & & & 0.010 \\
\hline$<50$ & $34(28.8)$ & $28(36.8)$ & $6(14.3)$ & \\
\hline$\geq 50$ & $84(71.2)$ & $48(63.2)$ & $36(85.7)$ & \\
\hline Age $(y r)^{*}$ & $55.7(10.5)$ & $52.67(9.0)$ & $61.1(10.8)$ & $<0.001$ \\
\hline Menopausal status & & & & 0.001 \\
\hline Premenopausal & $42(35.6)$ & $35(46.1)$ & $7(16.7)$ & \\
\hline Postmenopausal & $76(64.1)$ & $41(54.0)$ & $35(83.3)$ & \\
\hline Past or current smoker & $1(0.8)$ & $1(1.3)$ & 0 & $1.000^{\dagger}$ \\
\hline Tstage & & & & $0.604^{\dagger}$ \\
\hline 1 & $76(64.4)$ & $46(60.5)$ & $30(71.4)$ & \\
\hline 2 & $31(26.3)$ & $22(29.0)$ & $9(21.4)$ & \\
\hline 3 & $5(4.2)$ & $3(3.9)$ & $2(4.8)$ & \\
\hline Missing & $6(5.1)$ & $5(6.6)$ & $1(2.4)$ & \\
\hline $\mathrm{N}$ stage & & & & $0.434^{\dagger}$ \\
\hline 0 & $74(62.7)$ & $48(63.2)$ & $26(61.9)$ & \\
\hline 1 & $22(18.6)$ & $13(17.1)$ & $9(21.4)$ & \\
\hline 2 & $7(6.0)$ & $3(4.0)$ & $4(9.6)$ & \\
\hline 3 & $11(9.3)$ & $8(10.4)$ & $3(7.1)$ & \\
\hline Missing & $4(3.4)$ & $4(5.3)$ & 0 & \\
\hline AJCC stage & & & & $0.251^{\dagger}$ \\
\hline 0 & $2(1.7)$ & 0 & $2(4.8)$ & \\
\hline 1 & $63(53.3)$ & $41(53.9)$ & $22(52.3)$ & \\
\hline 2 & $31(26.3)$ & $20(26.3)$ & $11(26.2)$ & \\
\hline 3 & $18(15.3)$ & $11(14.4)$ & $7(16.7)$ & \\
\hline Missing & $4(3.4)$ & $4(3.4)$ & 0 & \\
\hline Prior adjuvant chemotherapy & $72(61.0)$ & $52(68.4)$ & $20(47.6)$ & 0.027 \\
\hline Prior tamoxifen therapy & $51(43.2)$ & $33(43.4)$ & $18(42.9)$ & 0.953 \\
\hline $\mathrm{BMI}\left(\mathrm{kg} / \mathrm{m}^{2}\right)$ at baseline & & & & $0.026^{\dagger}$ \\
\hline$<18.5$ & $1(0.9)$ & $1(1.3)$ & 0 & \\
\hline $18.5-24.9$ & $73(61.9)$ & $52(68.4)$ & $13(31.0)$ & \\
\hline $25-29.9$ & $27(22.9)$ & $12(15.8)$ & $25(59.5)$ & \\
\hline$\geq 50$ & $10(8.4)$ & $5(6.6)$ & $3(7.1)$ & \\
\hline Missing & $7(5.9)$ & $6(7.9)$ & $1(2.4)$ & \\
\hline $\operatorname{BMI}\left(\mathrm{kg} / \mathrm{m}^{2}\right)^{*}$ & $24.5(4.5)$ & $23.5(3.5)$ & $26.1(5.6)$ & 0.010 \\
\hline Type of Al & & & & $0.116^{\dagger}$ \\
\hline Letrozole & $67(56.8)$ & $45(59.2)$ & $22(52.4)$ & \\
\hline Anastrozole & $51(43.2)$ & $31(40.8)$ & $20(47.6)$ & \\
\hline Bisphosphonate use before breast cancer diagnosis & & & & 0.128 \\
\hline No & $114(96.6)$ & $75(98.7)$ & $39(92.9)$ & \\
\hline Yes & $4(3.4)$ & $1(1.3)$ & $3(7.1)$ & \\
\hline Current bisphosphonate supplementation & & & & 0.148 \\
\hline No & $99(83.9)$ & $61(80.3)$ & $38(90.5)$ & \\
\hline Yes & $19(16.1)$ & $15(19.7)$ & $4(9.5)$ & \\
\hline Vitamin D supplementation before breast cancer diagnosis & $2(1.7)$ & $2(2.6)$ & 0 & $1.000^{\dagger}$ \\
\hline \multicolumn{5}{|l|}{ Current vitamin D use } \\
\hline D3 base & $1(0.8)$ & $1(1.3)$ & 0 & $<0.001$ \\
\hline Vitamin D IV & $21(17.8)$ & $21(27.6)$ & 0 & $0.538^{\dagger}$ \\
\hline D3 base+vitamin D IV & $54(45.8)$ & $54(71.1)$ & 0 & $<0.001$ \\
\hline None & $42(35.6)$ & 0 & $42(100)$ & \\
\hline
\end{tabular}

Group 1 = Women who received vitamin D during Al therapy; Group 2 = Women who did not receive vitamin D during Al therapy; $\mathrm{Al}=$ aromatase inhibitor; $\mathrm{AJC}-$ $\mathrm{C}=$ American Joint Committee on Cancer; $\mathrm{BMI}=$ body mass index; IV = intravenous.

${ }^{*}$ Mean (SD); ${ }^{\dagger}$ Fisher's exact test. 
Table 2. Bone mineral density T-score of patients according to receipt of $\mathrm{Vi}$ tamin D therapy at baseline

\begin{tabular}{lccc}
\hline BMDT-score & $\begin{array}{c}\text { Group 1 } \\
(\mathrm{n}=76) \\
\text { No. }(\%)\end{array}$ & $\begin{array}{c}\text { Group 2 } \\
(\mathrm{n}=42) \\
\text { No. }(\%)\end{array}$ & p-value \\
\hline Baseline femoral neck & & & \\
$\leq-2.5$ & $3(3.9)$ & $8(19.0)$ & 0.037 \\
$-2.5<\mathrm{T}<-1.0$ & $32(42.2)$ & $12(28.6)$ & \\
$\geq-1.0$ & $40(52.6)$ & $22(52.4)$ & \\
Missing & $1(1.3)$ & 0 & \\
Mean \pm SD & $0.77 \pm 1.18$ & $-1.20 \pm 1.25$ & 0.069 \\
Baseline total proximal femur & & & \\
-2.5 & 0 & $1(2.4)$ & $0.061^{*}$ \\
$-2.5<\mathrm{T}<-1.0$ & $12(15.8)$ & $11(26.2)$ & \\
$\geq-1.0$ & $63(82.9)$ & $30(71.4)$ & \\
Missing & $1(1.3)$ & 0 & \\
Mean \pm SD & $0.03 \pm 1.14$ & $-0.48 \pm 1.2$ & 0.025 \\
Baseline lumbar spine & \multicolumn{3}{c}{0.142} \\
$\leq-2.5$ & $7(9.2)$ & $7(16.6)$ & \\
$-2.5<\mathrm{T}<-1.0$ & $35(46.1)$ & $12(28.6)$ & \\
$\geq-1.0$ & $34(44.7)$ & $23(54.8)$ & \\
Missing & 0 & 0 & \\
Mean \pm SD & $-0.80 \pm 1.46$ & $-0.98 \pm 1.4$ & 0.529 \\
\hline
\end{tabular}

Group $1=$ Women who received vitamin D during Al therapy; Group $2=$ Women who did not receive vitamin $\mathrm{D}$ during $\mathrm{Al}$ therapy; $\mathrm{Al}=$ aromatase inhibitor; $\mathrm{BMD}=$ bone mineral density.

*Fisher's exact test.

significant difference. Twenty-four months after AI therapy, the mean T-scores in the femoral neck ( $-1.10 \mathrm{vs.}-1.48, p=0.109)$, total proximal femur $(-0.10$ vs. $-0.55, p=0.074)$, and lumbar spine ( -1.23 vs. -1.25 , $p=0.943$ ) were higher in Group 1 compared to those in Group 2, without statistically significant difference.

Overall, both groups had some degree of bone loss over time, except for the T-score in the total proximal femur from 12 to 24 months (Table 4, Figure 1). In Group 1, the BMD T-score in the femoral neck decreased by a mean of 0.23 at 12 months and 0.40 at 24 months. In Group 2, the BMD T-score in the femoral neck decreased by a mean of 0.31 at 12 months and 0.44 at 24 months.

In Group 1, the BMD T-score decreased by a mean of 1.22 at 12 months and 0.17 at 24 months in the total proximal femur. However, the T-score increased by a mean of 1.05 from 12 to 24 months. In Group 2, the BMD T-score in the total proximal femur decreased by a mean of 0.74 at 12 months and 0.19 at 24 months. However, the T-score increased by a mean of 0.66 from 12 to 24 months. Differences in the change of BMD T-scores in the femoral neck, total proximal femur, and lumbar spine between the two groups were not statistically significant.
Table 3. Bone mineral density T-score of patients according to receipt of vitamin D therapy at 12 months and 24 months

\begin{tabular}{|c|c|c|c|}
\hline BMDT-score & $\begin{array}{l}\text { Group } 1 \\
(\mathrm{n}=76) \\
\text { No. }(\%)\end{array}$ & $\begin{array}{l}\text { Group 2 } \\
(n=42) \\
\text { No. }(\%)\end{array}$ & $p$-value \\
\hline Femoral neck at 12 months & & & 0.034 \\
\hline$\leq-2.5$ & $3(3.9)$ & $6(14.3)$ & \\
\hline$-2.5<\mathrm{T}<-1.0$ & $35(46.1)$ & $13(31.0)$ & \\
\hline$\geq-1.0$ & $31(40.8)$ & $14(33.3)$ & \\
\hline Missing & $7(9.2)$ & $9(21.4)$ & \\
\hline Mean \pm SD & $-1.00 \pm 1.02$ & $-1.38 \pm 1.13$ & 0.099 \\
\hline Total proximal femur at 12 months & & & 0.042 \\
\hline$\leq-2.5$ & $1(1.3)$ & $1(2.4)$ & \\
\hline$-2.5<\mathrm{T}<-1.0$ & $6(7.9)$ & $8(19.0)$ & \\
\hline$\geq-1.0$ & $62(81.6)$ & $24(57.2)$ & \\
\hline Missing & $7(9.2)$ & $9(21.4)$ & \\
\hline Mean \pm SD & $-0.09 \pm 1.00$ & $-0.44 \pm 1.07$ & 0.116 \\
\hline Lumbar spine at 12 months & & & 0.067 \\
\hline$\leq-2.5$ & $9(11.8)$ & $6(14.3)$ & \\
\hline$-2.5<\mathrm{T}<-1.0$ & $33(43.5)$ & $9(21.4)$ & \\
\hline$\geq-1.0$ & $27(35.5)$ & $18(42.9)$ & \\
\hline Missing & $7(9.2)$ & $9(21.4)$ & \\
\hline Mean $\pm S D$ & $1.19 \pm 1.25$ & $-1.13 \pm 1.19$ & 0.819 \\
\hline Femoral neck at 24 months & & & 0.053 \\
\hline$\leq-2.5$ & $2(2.6)$ & $6(14.2)$ & \\
\hline$-2.5<\mathrm{T}<-1.0$ & $34(44.7)$ & $12(28.6)$ & \\
\hline$\geq-1.0$ & $23(30.3)$ & $12(28.6)$ & \\
\hline Missing & $17(22.4)$ & $12(28.6)$ & \\
\hline Mean \pm SD & $-1.10 \pm 0.96$ & $-1.48 \pm 1.21$ & 0.109 \\
\hline Total proximal femur at 24 month & & & 0.032 \\
\hline$\leq-2.5$ & 0 & $3(7.1)$ & \\
\hline$-2.5<\mathrm{T}<-1.0$ & $6(7.9)$ & $6(14.3)$ & \\
\hline$\geq-1.0$ & $53(69.7)$ & $21(50.0)$ & \\
\hline Missing & $17(22.4)$ & $12(28.6)$ & \\
\hline Mean \pm SD & $-0.10 \pm 0.88$ & $-0.55 \pm 1.21$ & 0.074 \\
\hline Lumbar spine at 24 months & & & 0.022 \\
\hline$\leq-2.5$ & $3(3.9)$ & $7(16.7)$ & \\
\hline$-2.5<\mathrm{T}<-1.0$ & $36(47.4)$ & $10(23.7)$ & \\
\hline$\geq-1.0$ & $20(26.3)$ & $13(31.0)$ & \\
\hline Missing & $17(22.4)$ & $12(28.6)$ & \\
\hline Mean \pm SD & $-1.23 \pm 1.03$ & $-1.25 \pm 1.25$ & 0.943 \\
\hline
\end{tabular}

Group $1=$ Women who received vitamin D during Al therapy; Group $2=$ Women who did not receive vitamin D during Al therapy; $\mathrm{Al}=$ aromatase inhibitor; $\mathrm{BMD}=$ bone mineral density.

\section{DISCUSSION}

Our study compared the BMD changes in 118 postmenopausal women with breast cancer who had received adjuvant AI therapy ac- 
Table 4. Serial changes in bone mineral density and vitamin D use in patients receiving aromatase inhibitor therapy

\begin{tabular}{lccc}
\hline Changes in BMD T-score & $\begin{array}{c}\text { Group 1 } \\
(\mathrm{n}=76) \\
\text { Mean } \pm \text { SD }\end{array}$ & $\begin{array}{c}\text { Group 2 } \\
(\mathrm{n}=42) \\
\text { Mean } \pm \text { SD }\end{array}$ & -value \\
\hline Femoral neck & & & \\
From baseline to 12 months & $-0.23(0.41)$ & $-0.31(0.57)$ & $0.460^{*}$ \\
From baseline to 24 months & $-0.40(0.5)$ & $-0.44(0.63)$ & $0.673^{*}$ \\
From 12 to 24 months & $-0.14(0.3)$ & $-0.12(0.37)$ & $0.512^{*}$ \\
Total proximal femur & & & \\
From baseline to 12 months & $-1.22(0.99)$ & $-0.74(1.11)$ & $0.377^{*}$ \\
From baseline to 24 months & $-0.17(0.91)$ & $-0.19(1.01)$ & $0.853^{*}$ \\
From 12 to 24 months & $1.05(1.15)$ & $0.66(1.37)$ & $0.838^{*}$ \\
Lumbar spine & & & \\
From baseline to 12 months & $-0.41(0.59)$ & $-0.23(0.74)$ & $0.071^{*}$ \\
From baseline to 24 months & $-0.55(0.94)$ & $-0.32(1.42)$ & $0.189^{*}$ \\
From 12 to 24 months & $-0.08(0.77)$ & $-0.04(1.42)$ & $0.604^{*}$ \\
\hline
\end{tabular}

Group $1=$ Women who received vitamin D during Al therapy; Group $2=$ Women who did not receive vitamin $\mathrm{D}$ during $\mathrm{Al}$ therapy; $\mathrm{Al}=$ aromatase inhibitor; $\mathrm{BMD}=$ bone mineral density.

*Adjusted for age, menopausal status, prior adjuvant chemotherapy, prior and current bisphosphonate use, and baseline BMI using the generalized linear model (or ANCOVA).

cording to receipt of vitamin D therapy and had sequential measurements of BMD. We observed an average decrease of 1.10 in the T-score in the femoral neck in Group 1 and an average decrease of 1.48 in that in Group 2 at 24 months. The results were similar in the proximal femur and lumbar spine, showing decreases in BMD score at 24 months. However, there were no statistically significant differences in T-score changes according to receipt of vitamin D therapy.

These results are consistent with previously reported rates of bone loss in 12 months in postmenopausal women receiving AI therapy in the absence of antiresorptive therapy. Vitamin D status is a special concern in patients with breast cancer receiving AI therapy because of the vitamin's relationship to BMD $[11,12]$. Women receiving AI therapy are at an increased risk of decreased BMD and fracture. One cohort study found that after 5 years of anastrozole, there was a $6.08 \%$ decrease in median BMD in the lumbar spine and a 7.24\% decrease in the total hip [13]. Breast cancer survivors on AIs also have a 2.03-fold increased risk of any type of fracture compared to nonusers [14]. Other studies have reported bone loss in women receiving AI therapy, in the range of approximated 3\% (total hip) and 2\% (lumbar spine) per year [9]. They also noted that higher rates of bone loss at the hip and
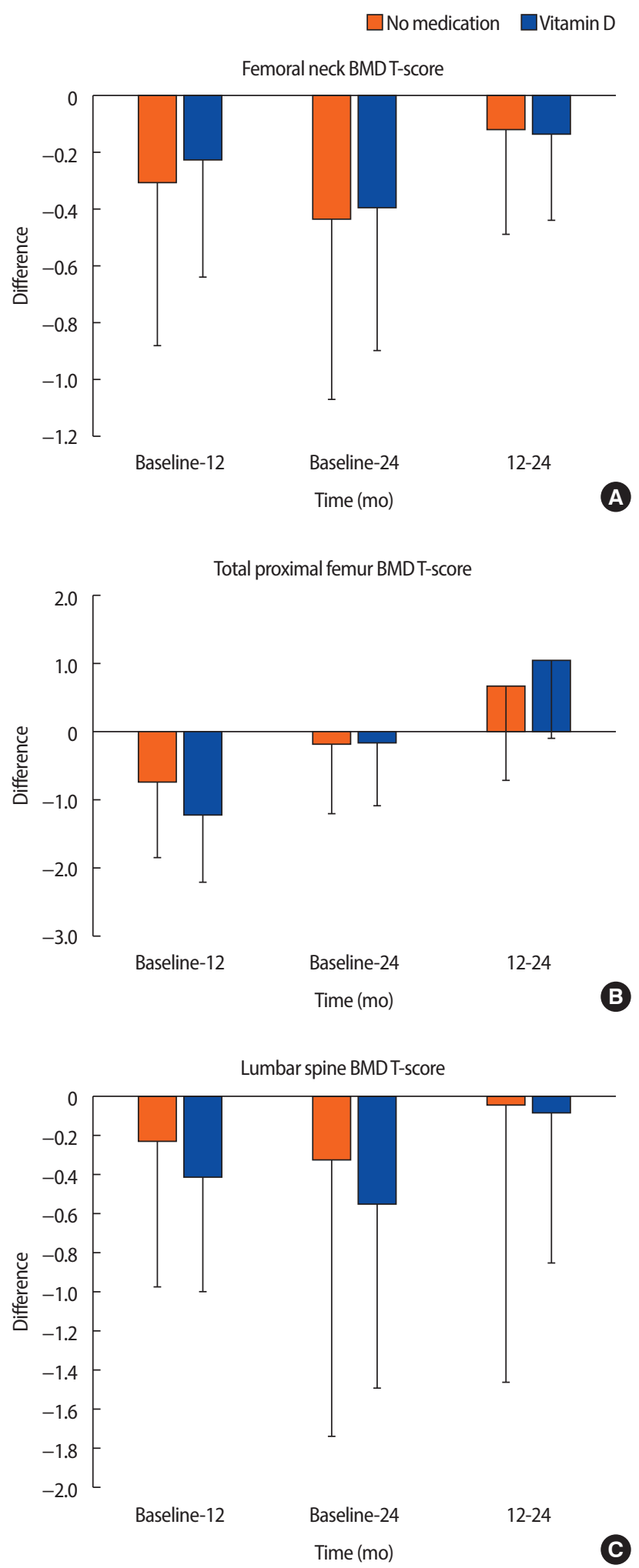

Figure 1. The mean change in $B M D$ in the femoral neck (A), total proximal femur (B), and lumbar spine (C) from baseline to 12 months, baseline to 24 months, and 12 to 24 months in postmenopausal patients with breast cancer receiving adjuvant $\mathrm{Al}$ therapy who received or did not receive vitamin $\mathrm{D}$. 
especially the spine were noted in younger ( $<55$ years) compared with older ( $\geq 75$ years) women after initiating or continuing AI therapy. Given the evidence that vitamin D may prevent osteoporotic fractures $[15,16]$, it may be important to understand how much vitamin D supplementation may help prevent osteoporosis and fracture in this population.

Several studies also reported the outcome of densitometry after vitamin D supplementation in postmenopausal patients with breast cancer receiving AI therapy. Tanaka et al. [17] reported that effectiveness of bisphosphonates combined with activated vitamin D administered for AI-induced osteoporosis after breast cancer surgery and primary postmenopausal osteoporosis through propensity score matching. Forty-eight postmenopausal patients with estrogen-receptor-positive early breast cancer, who received postoperative adjuvant AI treatment and whose BMD T-score decreased below -2.5 (AI group) and 48 patients with primary postmenopausal osteoporosis (PO group) were enrolled in this retrospective observational study. The actual measured BMD values in the lumbar spine increased with time compared with the baseline values in each group $(p<0.01)$. There was no significant difference in the actual measured BMD value or percentage BMD change in the lumbar spine in the groups. These results suggest that bisphosphonate therapy combined with activated Vitamin D therapy is effective in AI-induced osteoporosis as in postmenopausal osteoporosis. Prieto-Alhambra et al. [18] evaluated vitamin D supplementation and bone loss in normal women or those with osteopenia receiving AI therapy but not treated bisphosphonate therapy. After 3 months of supplementation, each $10 \mathrm{ng} / \mathrm{mL}$ increase in vitamin $\mathrm{D}$ resulted in a $0.5 \%(95 \%$ confidence interval $[\mathrm{CI}], 0.26-$ 0.75) lower BMD loss at the lumbar spine. Rastelli et al. [19] evaluated the effects of high-dose vitamin D on AI-induced musculoskeletal symptoms and bone loss in 60 women with HR+ invasive, nonmetastasized breast cancer. After 6 months, the placebo group had a BMD loss of $0.36 \% \pm 0.75$ (SEM) at the lumbar spine and $1.39 \% \pm 0.66$ at the femoral neck but BMD gain of $0.04 \% \pm 0.63$ at the total femur, whereas women in the vitamin D group gained BMD at the lumbar spine $(0.12$ $\pm 0.82)$ and femoral neck $(0.45 \pm 0.72)$ but lost BMD at the total femur $(-0.005 \% \pm 0.69)$.

Our results also suggest that vitamin D3, whether given orally or IV to postmenopausal women starting adjuvant letrozole therapy, results in clinically significant improvements in bone health. Although our findings strongly suggest that vitamin D protects against AI-associated bone loss, they need to be confirmed in a randomized trial. There is an ongoing randomized study in patients with breast cancer and low $25(\mathrm{OH}) \mathrm{D}$ levels who are starting letrozole treatment (clinicaltrials. gov NCT00867217). They hypothesized that high-dose vitamin D3 will prevent the worsening of musculoskeletal symptoms and bone loss compared to standard-dose vitamin D3.

Manson et al. [20] reported the role of vitamin D in the prevention of cancer and cardiovascular disease. They conducted a randomized, placebo-controlled trial to determine whether vitamin D supplementation reduces the risk of cancer or cardiovascular disease and found that vitamin D supplementation was not associated with a lower risk of these events. Cancer was diagnosed in 793 patients in the vitamin D group and 824 patients in the placebo group (hazard ratio [HR], 0.96; $95 \%$ CI, 0.88 to $1.06 ; p=0.47)$. A major cardiovascular event occurred in 805 participants (396 in the vitamin D group and 409 in the placebo group; HR, 0.97; 95\% CI, 0.85 to $1.12 ; p=0.69$ ). Even though other studies confirmed that vitamin D supplementation was beneficial to cancer incidence and cardiovascular event occurrence [21,22], given the long latency for cancer development, a longer follow-up duration is necessary to ascertain potential effects.

This study has several limitations. First, it was performed at a single institution and has a retrospective design. It does not have information about ultraviolet exposure and nonendogenous sources of vitamin D. Additionally, we were unable to collect data on compliance with supplementation, as this information is usually not documented in sufficient detail. Third, we did not have data on lifestyle factors, such as exercise or dietary pattern, which could lead to a potential bias on the outcome. Finally, we did not have long-term follow-up data after 5 years of AI therapy.

Therefore, we found declining trends in femur and lumbar spine BMD among postmenopausal women with breast cancer who are receiving AI therapy. We did not find a protective role of vitamin D supplementation against bone loss with AI therapy. However, this outcome should be interpreted cautiously owing to the potential lack of data on lifestyle factors and short follow-up period. A longer follow-up period is necessary to determine whether vitamin D supplementation prevents bone loss during AI therapy. 


\section{CONFLICT OF INTEREST}

The authors declare that they have no competing interests.

\section{REFERENCES}

1. Coombes RC, Kilburn LS, Snowdon CF, Paridaens R, Coleman RE, Jones SE, et al. Survival and safety of exemestane versus tamoxifen after 2-3 years' tamoxifen treatment (intergroup exemestane study): a randomised controlled trial. Lancet 2007;369:559-70.

2. Crew KD, Greenlee H, Capodice J, Raptis G, Brafman L, Fuentes D, et al. Prevalence of joint symptoms in postmenopausal women taking aromatase inhibitors for early-stage breast cancer. J Clin Oncol $2007 ; 25: 3877-83$

3. Ross AC, Taylor CL, Yaktine AL, Del Valle HB. Dietary reference intakes for calcium and vitamin D. Washington: National Academies Press; 2011

4. Vieth R, Bischoff-Ferrari H, Boucher BJ, Dawson-Hughes B, Garland CF, Heaney RP, et al. The urgent need to recommend an intake of vitamin D that is effective. Am J Clin Nutr 2007;85:649-50.

5. Runowicz CD, Leach CR, Henry NL, Henry KS, Mackey HT, Cowens-Alvarado RL, et al. American Cancer Society/American society of clinical oncology breast cancer survivorship care guideline. J Clin Oncol 2016;34:611-35

6. Gralow JR, Biermann JS, Farooki A, Fornier MN, Gagel RF, Kumar $\mathrm{R}$, et al. NCCN task force report: bone health in cancer care. J Natl Compr Canc Netw 2013;11 Suppl 3:S1-50; quiz S1.

7. Murad MH, Elamin KB, Abu Elnour NO, Elamin MB, Alkatib AA, Fatourechi MM, et al. Clinical review: the effect of vitamin D on falls: a systematic review and meta-analysis. J Clin Endocrinol Metab 2011;96:2997-3006.

8. Dawson-Hughes B, Harris SS, Krall EA, Dallal GE. Effect of calcium and vitamin D supplementation on bone density in men and women 65 years of age or older. N Engl J Med 1997;337:670-6.

9. Kwan ML, Yao S, Laurent CA, Roh JM, Quesenberry CP Jr, Kushi $\mathrm{LH}$, et al. Changes in bone mineral density in women with breast cancer receiving aromatase inhibitor therapy. Breast Cancer Res Treat 2018;168:523-30.

10. Khan QJ, Reddy PS, Kimler BF, Sharma P, Baxa SE, O'Dea AP, et al. Effect of vitamin D supplementation on serum 25-hydroxy vitamin
D levels, joint pain, and fatigue in women starting adjuvant letrozole treatment for breast cancer. Breast Cancer Res Treat 2010;119:1118.

11. Wang-Gillam A, Miles DA, Hutchins LF. Evaluation of vitamin D deficiency in breast cancer patients on bisphosphonates. Oncologist 2008;13:821-7.

12. Bang HW, Lim ST, Jeon YW, Suh YJ. Correlation between Serum 1,25-Dihydroxyvitamin D Levels and breast cancer prognosis in Korea. J Breast Dis 2015;3:37-42.

13. Eastell R, Adams JE, Coleman RE, Howell A, Hannon RA, Cuzick J, et al. Effect of anastrozole on bone mineral density: 5-year results from the anastrozole, tamoxifen, alone or in combination trial 18233230. J Clin Oncol 2008;26:1051-7.

14. Vestergaard P, Rejnmark L, Mosekilde L. Effect of tamoxifen and aromatase inhibitors on the risk of fractures in women with breast cancer. Calcif Tissue Int 2008;82:334-40.

15. Bergman GJ, Fan T, McFetridge JT, Sen SS. Efficacy of vitamin D3 supplementation in preventing fractures in elderly women: a meta-analysis. Curr Med Res Opin 2010;26:1193-201.

16. Bischoff-Ferrari HA, Willett WC, Wong JB, Giovannucci E, Dietrich T, Dawson-Hughes B. Fracture prevention with vitamin D supplementation: a meta-analysis of randomized controlled trials. JAMA 2005;293:2257-64

17. Tanaka M, Itoh S, Takeuchi Y. Effectiveness of bisphosphonate combined with activated vitamin $\mathrm{D}$ in patients with aromatase inhibitor-induced osteoporosis after breast cancer operation. Osteoporos Sarcopenia 2018;4:102-8.

18. Prieto-Alhambra D, Servitja S, Javaid MK, Garrigos L, Arden NK, Cooper C, et al. Vitamin D threshold to prevent aromatase inhibitor-related bone loss: the B-ABLE prospective cohort study. Breast Cancer Res Treat 2012;133:1159-67.

19. Rastelli AL, Taylor ME, Gao F, Armamento-Villareal R, Jamalabadi-Majidi S, Napoli N, et al. Vitamin D and aromatase inhibitor-induced musculoskeletal symptoms (AIMSS): a phase II, double-blind, placebo-controlled, randomized trial. Breast Cancer Res Treat 2011;129:107-16.

20. Manson JE, Cook NR, Lee IM, Christen W, Bassuk SS, Mora S, et al. Vitamin D supplements and prevention of cancer and cardiovascular disease. N Engl J Med 2019;380:33-44

21. Lappe J, Watson P, Travers-Gustafson D, Recker R, Garland C, Gor- 
ham E, et al. Effect of vitamin D and calcium supplementation on cancer incidence in older women: a randomized clinical trial. JAMA 2017;317:1234-43.

22. Scragg R, Khaw KT, Toop L, Sluyter J, Lawes CMM, Waayer D, et al.
Monthly high-dose vitamin D supplementation and cancer risk: a post hoc analysis of the vitamin D assessment randomized clinical trial. JAMA Oncol 2018;4:e182178. 